\title{
PH-sensitive and folic acid-targeted MPEG-PHIS/ FA-PEG-VE mixed micelles for the delivery of PTX-VE and their antitumor activity
}

This article was published in the following Dove Press journal:

International Journal of Nanomedicine

16 August 2017

Number of times this article has been viewed

\author{
Yan $\mathrm{Di}^{\mathrm{I}}$ \\ Ting $\mathrm{Li}^{\prime}$ \\ Zhihong Zhu' \\ Fen Chen ${ }^{2}$ \\ Lianqun $\mathrm{Jia}^{2}$ \\ Wenbing Liu $^{3}$ \\ Xiumei Gai \\ Yingying Wang' \\ Weisan Pan' \\ Xinggang Yang' \\ 'Department of Pharmaceutics, School \\ of Pharmacy, Shenyang Pharmaceutical \\ University, ${ }^{2}$ Key Laboratory of \\ Ministry of Education for TCM \\ Viscera-State Theory and Applications, \\ Liaoning University of Traditional \\ Chinese Medicine, ${ }^{3}$ Key Laboratory \\ of Structure-Based Drug Design \& \\ Discovery, Shenyang Pharmaceutical \\ University, Ministry of Education, \\ Shenyang, China
}

Correspondence: Xinggang Yang Department of Pharmaceutics, School of Pharmacy, Shenyang Pharmaceutical University, No 103 Wenhua Road,

Shenyang II0016, China

Tel +86244352 052I

Email yangxg123@163.com
Abstract: The aim of this study was to simultaneously introduce $\mathrm{pH}$ sensitivity and folic acid (FA) targeting into a micelle system to achieve quick drug release and to enhance its accumulation in tumor cells. Paclitaxel-(+)- $\alpha$-tocopherol (PTX-VE)-loaded mixed micelles (PHIS/FA/PM) fabricated by poly(ethylene glycol) methyl ether-poly(histidine) (MPEG-PHIS) and folic acidpoly(ethylene glycol)-(+)- $\alpha$-tocopherol (FA-PEG-VE) were characterized by dynamic light scattering and transmission electron microscopy (TEM). The mixed micelles had a spherical morphology with an average diameter of $137.0 \pm 6.70 \mathrm{~nm}$ and a zeta potential of $-48.7 \pm 4.25 \mathrm{mV}$. The drug encapsulation and loading efficiencies were $91.06 \% \pm 2.45 \%$ and $5.28 \% \pm 0.30 \%$, respectively. The $\mathrm{pH}$ sensitivity was confirmed by changes in particle size, critical micelle concentration, and transmittance as a function of $\mathrm{pH}$. MTT assay showed that PHIS/FA/PM had higher cytotoxicity at $\mathrm{pH} 6.0$ than at $\mathrm{pH} 7.4$, and lower cytotoxicity in the presence of free FA. Confocal laser scanning microscope images demonstrated a time-dependent and FA-inhibited cellular uptake. In vivo imaging confirmed that the mixed micelles targeted accumulation at tumor sites and the tumor inhibition rate was $85.97 \%$. The results proved that the mixed micelle system fabricated by MPEG-PHIS and FA-PEG-VE is a promising approach to improve antitumor efficacy.

Keywords: $\mathrm{pH}$ sensitive, folic acid targeting, mixed micelles, drug delivery, in vivo antitumor activity

\section{Introduction}

Nowadays, chemotherapy is considered as one of the most effective methods of cancer treatment. ${ }^{1,2}$ However, the development of chemotherapy treatment has been severely hindered by high systemic toxicity and low antitumor efficacy. The major reason for systemic toxicity is nonspecific distribution of antitumor agents throughout the body. ${ }^{3,4}$ However, multidrug resistance (MDR), either intrinsic or acquired upon repeated chemotherapy cycles, decreases the antitumor efficacy of antitumor agents. This decrease has been attributed to overexpression of superfamily of ATP-binding cassette $(\mathrm{ABC})$ proteins, including $\mathrm{P}$-glycoprotein (P-gp) and multidrug resistance-associated protein (MRP), resulting in increased cellular efflux of antitumor agents. ${ }^{5,6}$

In order to solve these problems, pharmaceutical researchers have put forward a hypothesis that a high dose of drug accumulates at cellular level rather than at systemic level. Therefore, polymeric micelles as a drug-delivery system have drawn more attentions due to their tumor targeting efficiency and responses to tumor microenvironment. ${ }^{7-9}$ Solid tumors are often characterized by overexpression of specific antigens or receptors on cell surfaces. ${ }^{10-12}$ Therefore, tumor selective ligands have been modified on the surface of micelles to improve antitumor efficacy and reduce toxicity, resulting from 
increasing intercellular drug level in tumors. ${ }^{13-15}$ Despite the efficient tumor targeting achieved, relatively slow drug release at tumor sites and intracellular internalization barriers have been considered as major problems, especially for MDR tumor cells. ${ }^{16,17}$ After micelles internalization into tumor cells by receptor-mediated endocytosis, the micelles become localized inside the endosomes and later would be trafficked into lysosomes..$^{18}$ Both these compartments are provided with acidic conditions and multitudinous enzymes. Hence, micelles might eventually be digested by enzymes or transported out of the cells via exocytosis, if they cannot escape from these acidic compartments. ${ }^{19}$

Therefore, it is urgent to find a new micelle-delivery system for intracellular targeting based on triggered release mechanism to achieve maximal therapeutic efficacy. ${ }^{20,21}$ It has been reported that the extracellular $\mathrm{pH}$ of most of the tumor tissues ( $\mathrm{pH}$ 6.5-7.2) is lower than that of normal tissues and blood stream ( $\mathrm{pH} 7.4) .{ }^{22-24}$ Moreover, intracellular organelles such as endosomes and lysosomes develop more acidic environment ( $\mathrm{pH} 4.5-6.0) .{ }^{25}$ Therefore, $\mathrm{pH}$-sensitive micelles have been chosen as the most attractive candidate to deliver antitumor agents to the cytoplasm or the nucleus where they are supposed to function. Among them, poly(histidine) (PHIS) is a promising "proton sponge" polymer, ${ }^{26-28}$ because the imidazole ring endows PHIS with an amphoteric nature by protonation-deprotonation, ${ }^{29,30}$ which makes micelles escape from endosomes/lysosomes and trigger the accelerated release of encapsulated drugs. However, PHIS is too sensitive to environmental $\mathrm{pH}$ that may influence the stability of micelles at normal $\mathrm{pH}$.

In order to tailor the triggering $\mathrm{pH}$ of the PHIS-based micelles to a lower $\mathrm{pH}$ of the tumor and increase the stability of the micelles at physiological $\mathrm{pH}$, mixed micelles with another amphiphilic polymer had been constructed. ${ }^{31-33}$ Hence, the $\mathrm{pH}$-sensitive mixed micelles have been integrated with active targeting function in order to further enhance drug delivery. ${ }^{34-36}$ This has been partially proven through the mixed micelles composed of PHIS-PEG and folic acid (FA)-conjugated poly(L-lactic acid) (PLLA)-PEG (FAPEG-PLLA). ${ }^{27}$ The mixed micelles were destabilized at a $\mathrm{pH}$ ranging from 6.5 to 7 , demonstrating a high cytotoxicity against tumor cells after folate-mediated endocytosis.

In this study, we aimed to prepare a mixed micelle delivery system composed of $\mathrm{pH}$-sensitive polymers and FA-targeted polymers. Paclitaxel-(+)- $\alpha$-tocopherol (PTX-VE) synthesized in a previous work was chosen as a model drug, ${ }^{37}$ which was encapsulated into the mixed micelles fabricated of synthesized poly(ethylene glycol) methyl ether-poly(histidine) (MPEG-PHIS) and folic acid-poly(ethylene glycol)
-(+)- $\alpha$-tocopherol (FA-PEG-VE). The characteristics of the mixed micelles such as particle size, zeta potential, and $\mathrm{pH}$ sensitivity were tested. $\mathrm{pH}$ sensitivity and FA targeting of the mixed micelles were tested by in vitro cytotoxicity and cell uptake experiments. Most importantly, in vivo imaging and pharmacodynamic experiments were carried out to test the antitumor efficacy of mixed micelles.

\section{Materials and methods Materials}

PTX-VE and sulforhodamine B-(+)- $\alpha$-tocopherol (SRB-VE) were synthesized in our laboratory (Figure S1). ${ }^{37,38}$ FAPEG-VE was synthesized according to a previous work. ${ }^{39}$ The synthetic route and ${ }^{1} \mathrm{H}-\mathrm{NMR}$ characterization of MPEG-PHIS is shown in Figures S2 and S3. PTX was purchased from Hengrui Pharmaceutical Co., Ltd (Jiangsu, China). 1,1'dioctadecyl-3,3,3',3'-tetramethylindotricarbocyanine iodide (DiR) was obtained from Fanbo Biochemicals (Beijing, China). FA was obtained from Longsheng Chemical Products Co., Ltd (Zhengzhou, China). Sodium carbonate $\left(\mathrm{Na}_{2} \mathrm{CO}_{3}\right)$ was obtained from Bodi Chemical Industry Co., Ltd (Tianjin, China). Acetone was obtained from Kexin Chemical Industry Co., Ltd (Tianjin, China). RPMI-1640 medium was obtained from Hyclone Co., Ltd and RPMI 1640 medium (free of FA) was obtained from Gibco (Thermo Fisher Scientific, Waltham, MA, USA). Fetal bovine serum was obtained from Sijiqing Co., Ltd (Hangzhou, China). 3-(4,5-dimethylthiazol2-yl)-2,5-diphenyl tetrazolium bromide (MTT) and trypsin were obtained from Sigma-Aldrich (St Louis, MO, USA).

\section{Preparation of mixed micelles}

An organic solvent evaporation method was used to prepare the mixed micelles by blending MPEG-PHIS with FAPEG-VE at a weight ratio of 40/60 (wt/wt\%). First, $0.8 \mathrm{mg}$ MPEG-PHIS was dissolved in $1.6 \mathrm{~mL}$ deionized water after sonication for $15 \mathrm{~min}$, and $1.2 \mathrm{mg}$ FA-PEG-VE was dissolved in $2.4 \mathrm{~mL}$ aqueous solution containing $0.1 \%(\mathrm{w} / \mathrm{v}) \mathrm{Na}_{2} \mathrm{CO}_{3}$. After that, a chosen amount of PTX-VE in $2 \mathrm{~mL}$ acetone was added slowly to the mixed water phase with continuous magnetic stirring at $50^{\circ} \mathrm{C}$ until the organic solvent had evaporated completely. Finally, the PTX-VE-loaded mixed micelles (PHIS/FA/PM) solution was obtained by passing through a $0.45 \mu \mathrm{m}$ syringe filter to remove aggregates and free drugs.

\section{Characterization of mixed micelles Determination of encapsulation and loading efficiencies (EE and LE)}

The EE and LE of PTX-VE in the mixed micelles were determined by HPLC. The HPLC system was equipped with 
a SPD-10AVP ultraviolet light detector (Shimadzu, Kyoto, Japan) and a C18 column $(4.6 \times 150$ mm, $5 \mu \mathrm{m}$; Dikma, Tianjin, China). The column was eluted with methanol/ water $(97: 3, \mathrm{v} / \mathrm{v})$ at a flow rate of $1.0 \mathrm{~mL} / \mathrm{min}$. PTX-VE was detected at $227 \mathrm{~nm}$ and the sample injection volume was kept constant at $20 \mu \mathrm{L}$. Each run was done in triplicate. The EE $(\%)$ and LE (\%) of the mixed micelles were calculated by the following equations:

$$
\mathrm{EE}(\%)=\frac{\text { Weight of drug encapsulated in micelles }}{\text { Weight of total drug }} \times 100 \%
$$

$$
\operatorname{LE}(\%)=\frac{\text { Weight of drug encapsulated in micelles }}{\text { Weight of drug and carrier }} \times 100 \%
$$

\section{Transmission electron microscopy (TEM)}

The surface morphology of PHIS/FA/PM was observed using a JEM-100SX electron microscope (JEOL, Tokyo, Japan). Briefly, a drop of micelle solution with a selected concentration was dropped onto a carbon-coated copper grid. A few minutes after the deposition, the extra solution was removed using a strip of filter paper and negative staining was performed with a droplet of $1 \%(\mathrm{w} / \mathrm{v})$ phosphotungstic acid for $1 \mathrm{~min}$. Then, the excess liquid was removed with a filter paper and dried prior to TEM observation. ${ }^{40}$

\section{Characterization of $\mathrm{pH}$-sensitivity of the mixed micelles}

$\mathrm{pH}$-dependent critical micelle concentrations (CMC)

The CMC of the mixed micelles was determined by fluorescence probe technique with pyrene as a probe. ${ }^{31,41}$ Aliquots of pyrene solution $\left(6 \times 10^{-6} \mathrm{M}, 1 \mathrm{~mL}\right)$ in acetone were added to volumetric flasks and the acetone was removed by vacuum drying followed by mixing with blank mixed micelle solutions dispersed in PBS ( $\mathrm{pH} 7.4,6.5,5.0)$ with concentrations ranging from $1 \times 10^{-4} \mathrm{mg} / \mathrm{mL}$ to $1 \times 10^{-1} \mathrm{mg} / \mathrm{mL}$. The final pyrene concentration in the copolymer solution was fixed at $6 \times 10^{-7} \mathrm{~mol} / \mathrm{L}$. All the solutions were then sonicated for $30 \mathrm{~min}$ and kept in dark for $24 \mathrm{~h}$ at room temperature to reach soluble equilibrium. The fluorescence of the soluble pyrene was measured at an excitation wavelength of $335 \mathrm{~nm}$ and an emission wavelength of $373 \mathrm{~nm}\left(\mathrm{I}_{1}\right)$ and $394 \mathrm{~nm}\left(\mathrm{I}_{5}\right)$, respectively, using a microplate reader (Thermo Scientific, Waltham, MA, USA). The CMC was determined by plotting the intensity ratio $\mathrm{I}_{394} / \mathrm{I}_{373}$ versus the logarithm of the copolymer solution concentration.
Particle size and zeta potential of the mixed micelles Dynamic light scattering (DLS) was used to determine the particle size, zeta potential, and size distribution of the mixed micelles. To investigate the $\mathrm{pH}$-sensitivity of the mixed micelles, the mixed micelles were exposed to $10 \mathrm{mM}$ PBS at different $\mathrm{pH}$ values ( $\mathrm{pH} 7.4,6.5$, and 5.0) for $15 \mathrm{~min}$ before the measurement. ${ }^{31}$ All the measurements were carried out on a Zetasizer Nano ZS90 (Malvern Instruments, Malvern, $\mathrm{UK}$ ) at $25^{\circ} \mathrm{C}$ after equilibration for $2 \mathrm{~min}$. Each measurement was performed in triplicate.

\section{Transmittance of the mixed micelles}

The $\mathrm{pH}$-dependent light transmittance of the mixed micelles was measured using a UV-Vis-8000 spectrophotometer (Yuan Analysis Instrument Co., Ltd, Shanghai, China) at $\lambda=500 \mathrm{~nm}$. The solution concentration was $0.1 \mathrm{~g} / \mathrm{L}$ and the initial $\mathrm{pH}$ was 9 . Then the $\mathrm{pH}$ was gradually decreased by adding $0.01 \mathrm{M} \mathrm{HCl}$ solution. Relative transmittance of the mixed micelles solution was obtained in a selected $\mathrm{pH}$ range with respect to a transmittance at $\mathrm{pH} 9.0 .^{26}$

\section{Cell tests in vitro}

\section{Cell cultures}

Human breast adenocarcinoma (MCF-7) cells were purchased from Cell Bank, Chinese Academy of Sciences. All cells were cultured in RPMI-1640 medium supplemented with $10 \%$ fetal bovine serum, penicillin $(100 \mu \mathrm{g} / \mathrm{mL})$, and streptomycin $(100 \mu \mathrm{g} / \mathrm{mL})$ at $37^{\circ} \mathrm{C}$ under a humidified atmosphere of $5 \% \mathrm{CO}_{2}$. Cells in the exponential phase of growth were used in the experiments.

\section{Cytotoxicity test}

The cytotoxicity tests were carried out at different times, different $\mathrm{pH}$ values, and different FA concentrations. Briefly, the cells were seeded at a concentration of $5 \times 10^{3}$ cells per well in a 96-well plate and incubated for $24 \mathrm{~h}$. After removing the culture medium, $200 \mu \mathrm{L}$ culture medium (FA-free) containing different concentrations of free PTX-VE or PTX-VE-loaded PHIS/FA mixed micelles (PHIS/FA/PM) were added to the plate. After further incubation for $24 \mathrm{~h}$ and $48 \mathrm{~h}$, cell viability was measured using MTT. For this, $20 \mu \mathrm{L}$ of MTT stock solutions $(5 \mathrm{mg} / \mathrm{mL})$ was added to each well, and then the cells were incubated for another $4 \mathrm{~h}$ at $37^{\circ} \mathrm{C}$. The medium was then removed and $150 \mu \mathrm{L}$ of dimethyl sulfoxide was added to solubilize the formazan crystals. The absorbance of each well was measured at $490 \mathrm{~nm}$ using a microplate reader (US Valley Molecular Instruments Co., Ltd, Shanghai, China).

In addition, to evaluate the $\mathrm{pH}$-sensitive characteristics of the mixed micelles, cytotoxicity was determined at different 
$\mathrm{pH}$ values. The $\mathrm{pH}$ of the culture medium was adjusted with $0.1 \mathrm{M} \mathrm{HCl}$ to the desired $\mathrm{pH}$ ( $\mathrm{pH} 7.4,6.5$, and 6.0). Various formulations (PHIS/FA/PM and free PTX-VE solution) containing different concentrations $(1,5$, and $10 \mu \mathrm{g} / \mathrm{mL})$ were added to the cells. After incubation for $48 \mathrm{~h}$, the cells were treated as discussed previously. Furthermore, FA inhibition cytotoxicity test was also carried out to evaluate the targeting capacity of FA of the mixed micelles to MCF-7 cells. The mixed micelles solutions at different concentrations $(0.5,5$, 10 , and $20 \mu \mathrm{g} / \mathrm{mL}$ ) diluted with RPMI-1640 medium (containing free-FA and $0.002,0.1,1 \mathrm{mM} \mathrm{FA}$ ) were added to the plate. After incubation for $24 \mathrm{~h}$, the cells were treated as discussed previously. The cell viability was calculated using the following equation:

$$
\text { Cell viability }(\%)=\frac{\mathrm{OD}_{\text {test }}-\mathrm{OD}_{\text {blank }}}{\mathrm{OD}_{\text {control }}-\mathrm{OD}_{\text {blank }}} \times 100 \%
$$

\section{Confocal laser scanning microscopy (CLSM)}

The cellular uptake of the mixed micelles was observed by CLSM (Carl Zeiss LSM 710; Carl Zeiss AG, Oberkochen, Germany). The insoluble fluorescent dye was encapsulated with SRB-VE instead of PTX-VE into the mixed micelles (PHIS/FA/SM). For this, MCF-7 cells were seeded on the sterile cover slip placed in a 24-well plate and incubated for $24 \mathrm{~h}$. Then, fresh FA-free RPMI-1640 medium containing free SRB-VE solution or PHIS/FA/SM (SRB-VE concentration was $4 \mu \mathrm{g} / \mathrm{mL}$ ) was added to the plate for further incubation for 1, 2, 4, and $6 \mathrm{~h}$. Beyond that, RPMI-1640 medium containing different concentrations of FA $(0.002,0.1$, and $1 \mathrm{mM})$ was added into each well and preincubated for $1 \mathrm{~h}$. Afterward, the medium was replaced by PHIS/FA/SM (SRB-VE concentration was $4 \mu \mathrm{g} / \mathrm{mL}$ ) along with different concentrations of FA and incubated for another $4 \mathrm{~h}$. The cells were washed three times with cold PBS and fixed with $4 \%$ paraformaldehyde for $30 \mathrm{~min}$ at room temperature. Then, the nuclei were stained with 4',6-diamidino-2-phenylindole (DAPI) for $5 \mathrm{~min}$. The coverslips were then mounted on microscope slides using a fluorescence-free buffered mounting medium prior to imaging. The excitation wavelength of DAPI and SRB-VE are $405 \mathrm{~nm}$ and $543 \mathrm{~nm}$, respectively.

\section{Animals and tumor model}

Female Kunming mice (20-25 g) were obtained from Shenyang Pharmaceutical University Animal Institution and were housed under standard conditions. All animal experiments were carried out in accordance with the Rules of Shenyang Pharmaceutical University Bioethics Committee and in compliance with the Guide for the Care and Use of Laboratory Animals of the national laws. The ethical committee approval number of animal studies is SYPU-IACUC-C2016-0629-101. Sarcoma-180 (S-180) cell suspension $\left(2 \times 10^{6}\right.$ cells in $0.2 \mathrm{~mL}$ saline) was implanted subcutaneously into mice via armpits to produce the tumor-bearing mouse model.

\section{In vivo tumor targeting imaging}

The in vivo distribution and targeting effect of the mixed micelles were investigated using a FX Pro in vivo imaging system (Carestream Health, Xiamen, China). The near infrared fluorescence dye DiR was used for fluorescence imaging. Tumor-bearing mice were established as described previously. DiR-loaded PHIS/FA micelles (PHIS/FA/DiR) or DiR in ethanol/water $(1: 4 \mathrm{v} / \mathrm{v})$ solution $(10 \mathrm{nmol} \mathrm{DiR})$ was intravenously injected into the tumor-bearing mice via a tail vein. ${ }^{42}$ The fluorescent images were recorded at 2, 4, 8, 12, 24, and $48 \mathrm{~h}$ post-injection. The mice anesthetized via inhalation of isoflurane were moved into the imaging chamber for scanning, with the following parameters for DiR: excitation at $720 \mathrm{~nm}$ and emission at $790 \mathrm{~nm}$. Ex vivo images of organs and tumors excised at $48 \mathrm{~h}$ post-injection were also obtained.

\section{In vivo tumor growth inhibition study}

Tumor-bearing mice were used to evaluate the antitumor efficacy. When the tumor volume reached $100-200 \mathrm{~mm}^{3}$, they were randomly assigned to four groups ( $n=5$ per group). The mice were treated at a 3-day interval (day 1, 4, 7, 10, 13) with saline, Taxol, PTX-VE, and PHIS/FA/PM. All formulations were injected intravenously via the tail vein at a dose of $5 \mathrm{mg} / \mathrm{kg}$. The tumor inhibitory activity was assessed with the tumor volume $\left(\mathrm{V}=L \times S^{2} / 2\right)$ and body weight, which were measured every other day. Here, $L$ is the length of the longest tumor axis ( $\mathrm{mm}$ ) and $S$ is the length of the shortest axis ( $\mathrm{mm})$ as measured by a slide caliper. Then, after a 15-day treatment, the mice were euthanized, and the tumors were excised and weighed. The tumor inhibition rate (TIR) was calculated by the equation $\left(W_{s}-W_{t}\right) / W_{s} \times 100 \%$, where $W_{t}$ is the tumor weight of the test group and $W_{s}$ is the tumor weight of the saline group.

\section{Results and discussion Preparation and characterization of the mixed micelles}

PTX-VE-loaded PHIS/FA mixed micelles fabricated from a mixture of two block copolymers MPEG-PHIS (40\%) and FA-PEG-VE (60\%) were successfully prepared by organic solvent evaporation method. The hydrophobic deprotonated 
PHIS and VE blocks formed a hydrophobic inner core due to hydrophobic interactions. A hydrophilic reticuloendothelial system block formed an outer shell to avoid clearance by the reticuloendothelial system and prolong the circulation time, and the fragment FA on the surface of the mixed micelles was aimed to target the folate receptors on the surface of tumor cells. It is well known that particle size is a main factor that determines blood circulation time by altering physiological processes. An optimum particle size of $<200 \mathrm{~nm}$ can avoid clearance by phagocytic uptake and hepatic filtration and favor tumor tissue accumulation through the enhanced permeability and retention effect. ${ }^{43}$ As shown in Figure 1A and B, the mixed micelles exhibited a uniform particle size distribution with a diameter of $137.0 \pm 6.70 \mathrm{~nm}$ and a zeta potential of $-48.7 \pm 4.25 \mathrm{mV}$. Data are expressed as mean $\pm \mathrm{SD}(\mathrm{n}=3)$. Drug EE and LE were $91.06 \% \pm 2.45 \%$ and $5.28 \% \pm 0.30 \%$, respectively. Additionally, the shape of micelles also has an influence on their delivery characteristics. ${ }^{44}$ As shown in Figure 2, the morphology of mixed micelles was homogeneous and spherical. However, the size of the mixed micelles observed by TEM was smaller than that measured by DLS. This may be due to the shrinkage of the micelles during the drying process when TEM samples were made..$^{45,46}$

\section{$\mathrm{pH}$ sensitivity of the mixed micelles}

Application of a mixed micelle system fabricated from a $\mathrm{pH}$-sensitive polymer and a $\mathrm{pH}$-insensitive polymer was an effective way to control and fine-tune $\mathrm{pH}$ sensitivity. ${ }^{34}$ To investigate the $\mathrm{pH}$-sensitive properties of the mixed micelles, $\mathrm{CMC}$, particle properties, and light transmittance were examined under different $\mathrm{pH}$ conditions. The change in the micropolarity of the mixed micelles as a function of $\mathrm{pH}$ was clearly related to the $\mathrm{pK}_{\mathrm{a}}$ of the copolymer. As $\mathrm{pH}$ decreased, the protonation of imidazole groups in the PHIS block caused a hydrophobic to hydrophilic transition and a progressive increase in the electrostatic repulsive force. ${ }^{27}$
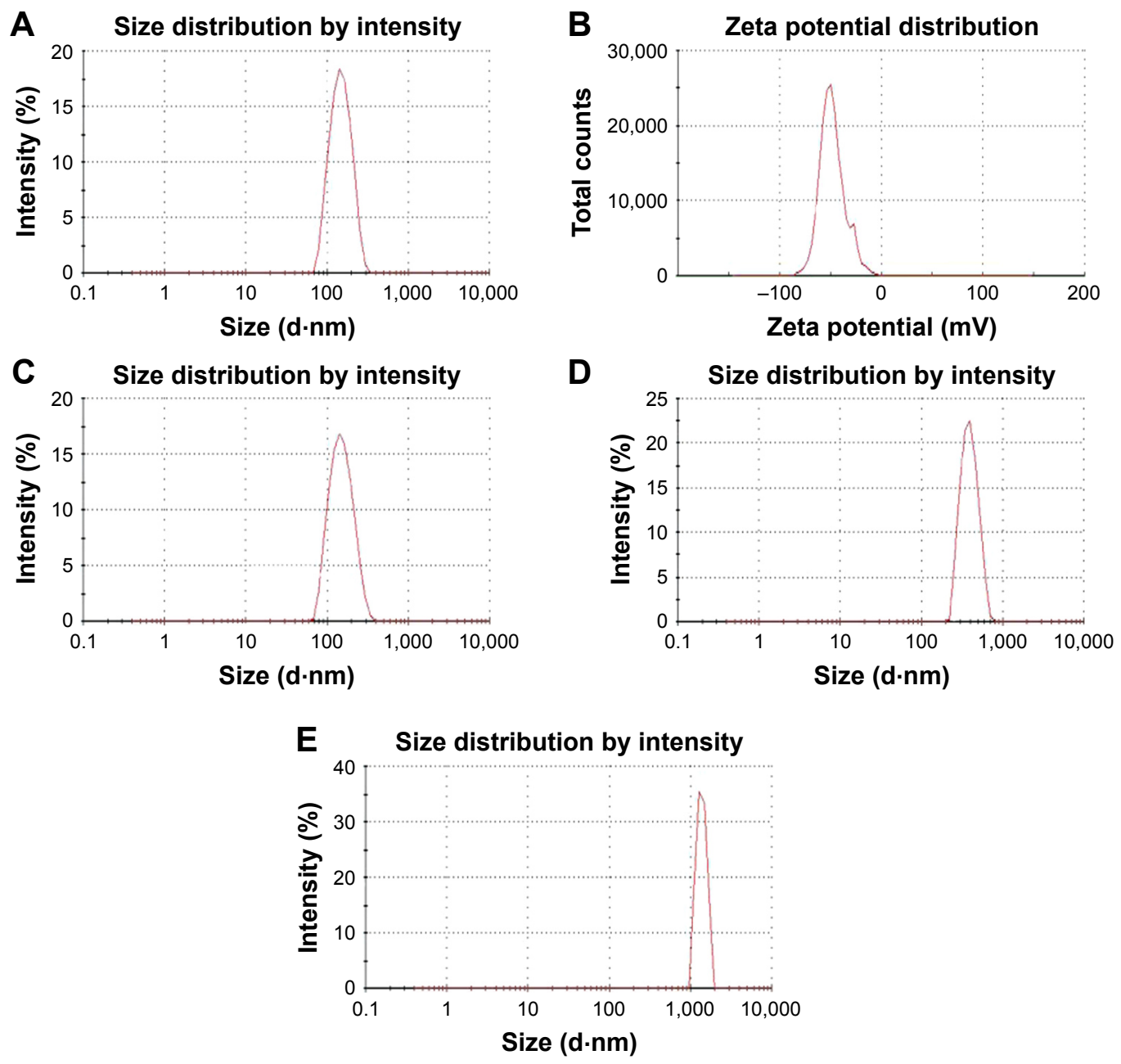

Figure I Size distribution of PHIS/FA/PM (A), zeta potential (B), and size distribution of PHIS/FA/PM under pH 7.4 (C), $\mathrm{pH} 6.5$ (D), and pH 5.0 (E). Abbreviations: PHIS, poly(histidine); FA, folic acid; PTX-VE, paclitaxel-(+)- $\alpha$-tocopherol; MPEG, poly(ethylene glycol) methyl ether; PHIS/FA/PM, PTX-VE-loaded MPEG-PHIS/FA-PEG-VE mixed micelles. 


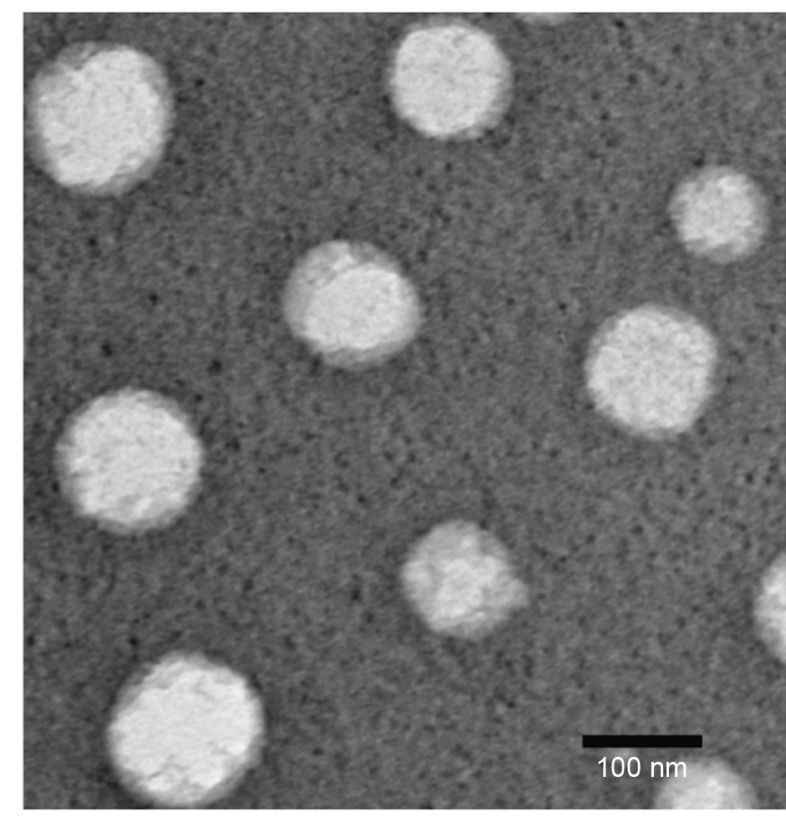

Figure 2 TEM image of PHIS/FA/PM. Magnification $\times 250$.

Abbreviations: TEM, transmission electron microscopy; PTX-VE, paclitaxel-(+)$\alpha$-tocopherol; MPEG, poly(ethylene glycol) methyl ether; PHIS, poly(histidine); FA, folic acid; PHIS/FA/PM, PTX-VE-loaded MPEG-PHIS/FA-PEG-VE mixed micelles.

Moreover, the combination of FA-PEG-VE was aimed to modulate the $\mathrm{pH}$ response values and make the micelle stable at $\mathrm{pH} 7.4$.

The CMC change induced by $\mathrm{pH}$ was investigated by standard pyrene method. Pyrene shows strong fluorescence intensity in a nonpolar environment, but weakly fluorescence in a polar environment. The change in the total emission intensity vs log concentration of mixed micelles indicates the formation of micelle or the change from micelle to unimer (dissociated polymer from disrupted micelle). ${ }^{31}$

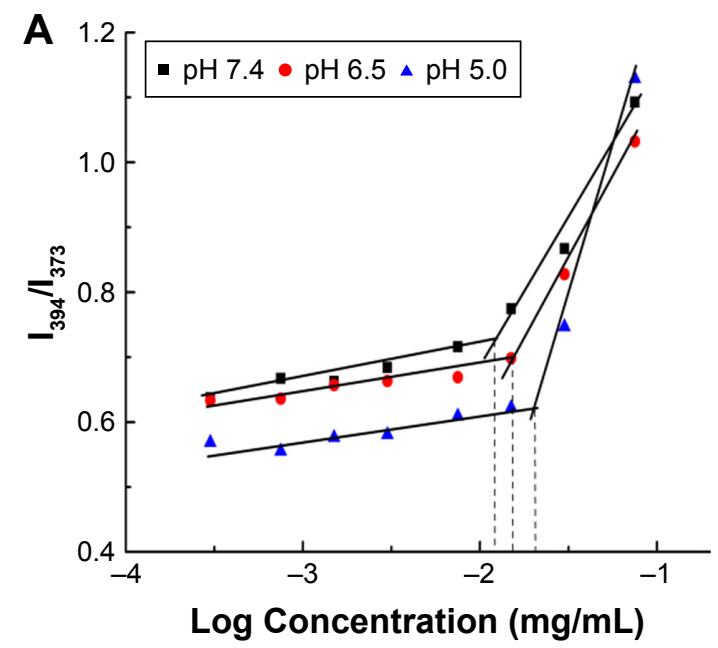

The influence of $\mathrm{pH}$ on the intensity ratio $\left(\mathrm{I}_{394} / \mathrm{I}_{373}\right)$ of pyrene is shown in Figure 3A; the CMC increased from 13.9 to $22.9 \mu \mathrm{g} / \mathrm{mL}$ when the $\mathrm{pH}$ decreased from 7.4 to 5.0 . It was demonstrated that as the $\mathrm{pH}$ of the mixed micelles solution decreased from 7.4 to 5.0, the imidazole groups of PHIS tended to ionize and became more hydrophilic. Therefore, the concentration of amphiphilic copolymers self-assembled into core-shell micelles needs to be larger.

The variations in the particle size of the mixed micelles induced by $\mathrm{pH}$ were examined by DLS, as shown in Table 1 and Figure 1C-E. Compared with the original formulation, at $\mathrm{pH} 7.4$, the average diameter of the mixed micelles changed only a little (from 137.0 to $145.3 \mathrm{~nm}$ ), and the size distribution remained uniform (polydispersity index [PDI] 0.113). Moreover, at $\mathrm{pH} 6.5$, the average diameter and size distribution gradually increased (size $375.4 \mathrm{~nm}$, PDI 0.186), indicating that the hydrophobic core PHIS began to ionize and tended to solubilize in aqueous solution. As the $\mathrm{pH}$ decreased to 5.0, the diameter of PHIS/FA/PM sharply increased from $137.0 \mathrm{~nm}$ to $1,404.5 \mathrm{~nm}$, and the particle size distribution was nonuniform (PDI 0.667). This could be due to the aggregation of FAPEG-VE after destabilization of mixed micelles at acidic $\mathrm{pH}{ }^{25}$ This suggested that mixed micelles could respond to acidic $\mathrm{PH}$ environment that makes it to swell further, which is beneficial in accelerating drug release from the micelle core. ${ }^{47}$

Furthermore, the change in the transmittance of the mixed micelles solution as a function of $\mathrm{pH}$ is shown in Figure 3B. With a decrease in the $\mathrm{pH}$ value, the relative transmittance of the micelle solution gradually decreased. With regard to the $\mathrm{pH}$-dependent structural change of mixed micelles, the PHIS/FA/PM remained stable at $\mathrm{pH} 7.4$ (physical $\mathrm{pH}$ ) and

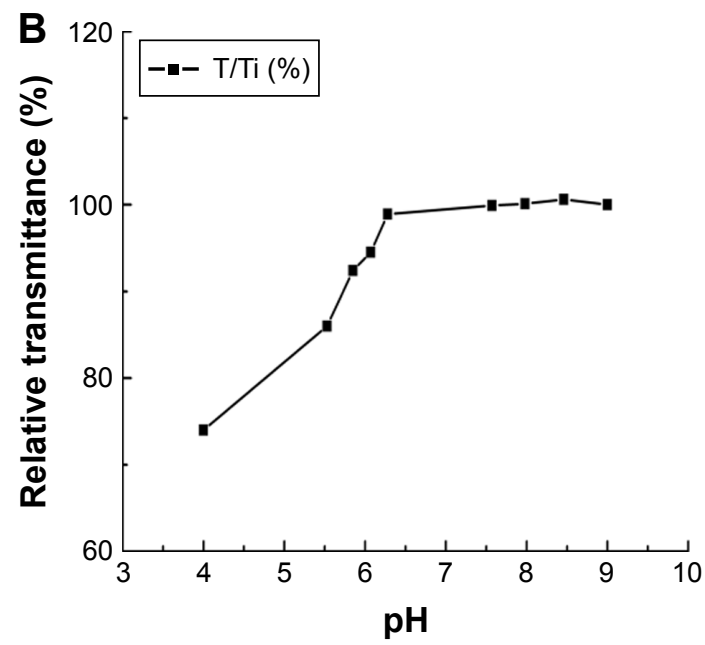

Figure 3 The fluorescence intensity ratio of $\mathrm{I}_{394} / \mathrm{I}_{373}$ from emission spectra vs log concentration of mixed micelles as a function of $\mathrm{pH}(\mathbf{A})$. The relative transmittance of $\mathrm{pH} 9.0(\lambda=500 \mathrm{~nm})(\mathbf{B})$. 
Table I Characteristics of PHIS/FA/PM at different $\mathrm{pH}$ conditions

\begin{tabular}{lll}
\hline PHIS/FA/PM & Particle size $(\mathbf{n m})$ & PDI \\
\hline $\mathrm{pH} 7.4$ & $145.3 \pm 5.0$ & $0.113 \pm 0.075$ \\
$\mathrm{pH} 6.5$ & $375.4 \pm 3.1$ & $0.186 \pm 0.046$ \\
$\mathrm{pH} 5.0$ & $1,404.5 \pm 519.7$ & $0.667 \pm 0.577$ \\
\hline
\end{tabular}

Notes: Paclitaxel-(+)- $\alpha$-tocopherol-loaded mixed micelles; data are expressed as mean \pm SD.

Abbreviations: FA, folic acid; PHIS, poly(histidine); PHIS/FA/PM, PTX-VE-loaded MPEG-PHIS/FA-PEG-VE mixed micelles; PDI, polydispersity index.

tended to depolymerize at pH 5.0 (lysosomes/endosomes in tumor cells), which plays an important role in accelerating drug release in tumor cells and reversing MDR. ${ }^{6}$

\section{Cytotoxicity assay}

The effect of the mixed micelles in cell viability was evaluated using MTT assay. ${ }^{48}$ The cell viabilities of MCF-7 cells after incubation with PTX-VE and PHIS/FA/PM for 24 and $48 \mathrm{~h}$ are shown in Figure 4A and B. We concluded that PTX-VE and PHIS/FA/PM had significant time-dependent and concentration-dependent growth inhibition effects on cancerous cells according to the $\mathrm{IC}_{50}$ value of the PTX-VE and PHIS/FA/PM after incubation for $48 \mathrm{~h}$ (10.33 vs $3.52 \mu \mathrm{g} / \mathrm{mL}$, respectively). Obviously, the cytotoxicity of micelle solution was higher than that of the corresponding free drug solution. This cytotoxicity developed by PTX-VE encapsulated into mixed micelles might be due to enhanced cellular uptake and accumulation in tumor cells.

The cytotoxicity of PHIS/FA/PM at different $\mathrm{pH}$ values, that is at normal tissue $\mathrm{pH}$ (7.4), tumor interstitial $\mathrm{pH}(6.5)$, and early endosomal compartment $\mathrm{pH}(<6.0)$, were also examined. ${ }^{31,49}$ As illustrated in Figure 4C, blank micelles and
A

$24 \mathrm{~h}$

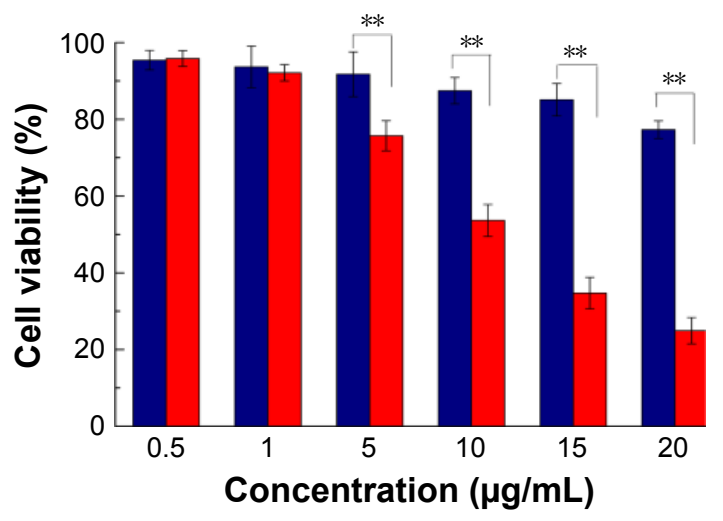

B

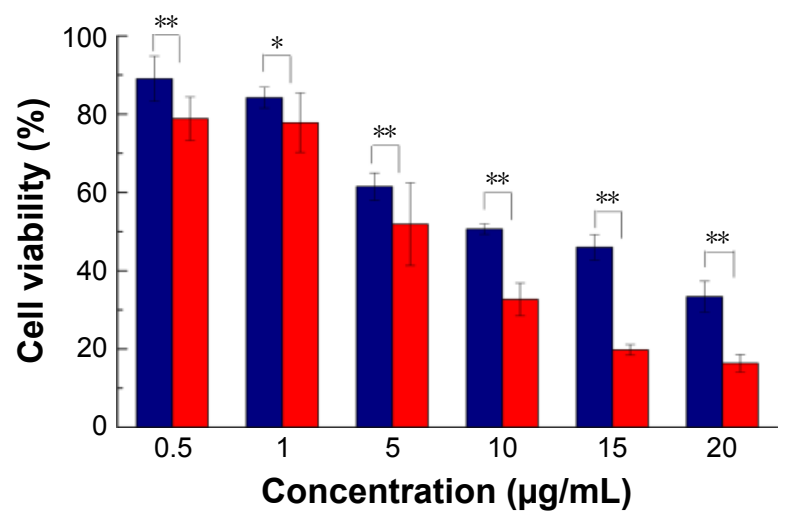

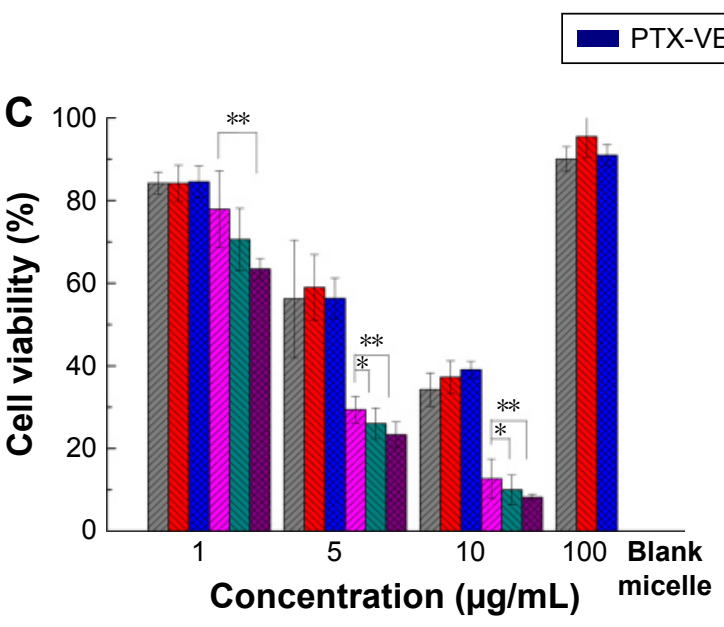

\begin{tabular}{|ll|}
\hline $\mathrm{pH}$ 7.4 PTX-VE & $\mathrm{pH} 6.5 \mathrm{PTX}-\mathrm{VE}$ \\
$\mathrm{pH}$ 6.0 PTX-VE & $\mathrm{pH}$ 7.4 PHIS/FA/PM \\
$\mathrm{pH}$ 6.5 PHIS/FA/PM & $\mathrm{pH}$ 6.0 PHIS/FA/PM
\end{tabular}

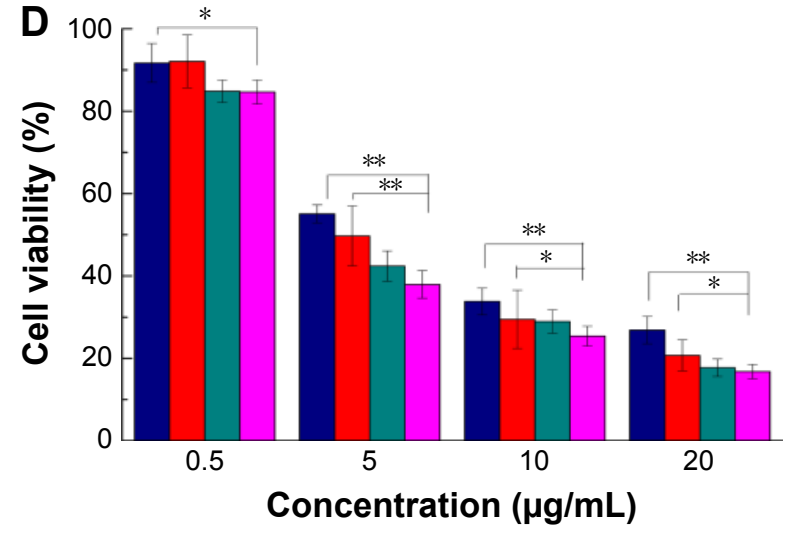

$1 \mathrm{mM} F A \quad 0.1 \mathrm{mM} F A$ 0.002 mM FA Free-FA

Figure 4 In vitro cell viability of PTX-VE and PHIS/FA/PM against MCF-7 cells after incubation for $24 \mathrm{~h}(\mathbf{A})$ and $48 \mathrm{~h}$ (B). Cell viability of PTX-VE, blank micelles, and PHIS/ FA/PM against MCF-7 cells at different $\mathrm{pH}$ values (7.4, 6.5, and 6.0) after incubation for $48 \mathrm{~h}(\mathbf{C})$. Cell viability of PHIS/FA/PM against MCF-7 cells at different concentrations of FA (free of FA, $0.002,0.1$, and I mM) after incubation for $24 \mathrm{~h}$ (D). Significant differences are indicated as follows: $* P<0.05$ and $* * P<0.01$.

Abbreviations: PTX-VE, paclitaxel-(+)- $\alpha$-tocopherol; MPEG, poly(ethylene glycol) methyl ether; PHIS, poly(histidine); FA, folic acid; PHIS/FA/PM, PTX-VE-loaded MPEG-PHIS/FA-PEG-VE mixed micelles. 
PTX-VE solution were treated as controls. No cytotoxicity against MCF-7 cells (after $48 \mathrm{~h}$ of incubation at three different $\mathrm{pH}$ values) was observed in blank mixed micelles (polymer concentration was $100 \mu \mathrm{g} / \mathrm{mL}$ ). PTX-VE solution treated against MCF-7 cells at three different $\mathrm{pH}$ values showed remarkable concentration-dependent cytotoxicity. However, there was no cytotoxic difference among different $\mathrm{pH}$ values. On the contrary, the cytotoxicity of the PHIS/FA/PM significantly increased with decreased $\mathrm{pH}$. This might be due to the fact that $\mathrm{pH}$-sensitive micelles facilitate drug release at acidic conditions and efficiently kill the tumor cell.

Furthermore, the effect of FA in inhibiting PHIS/FA/PM was also investigated. As shown in Figure 4D, the cytotoxicity of PHIS/FA/PM diluted with FA-free culture medium was higher than that of PHIS/FA/PM at different concentrations of FA $(0.002,0.1$, and $1 \mathrm{mM})$. With increased concentration of free FA, the cell viability also increased. The competition between free FA and PHIS/FA/PM decreased the internalization of PHIS/FA/PM against tumor cells.

Overall, PTX-VE-loaded PHIS/FA mixed micelles showed $\mathrm{pH}$ excellent responsiveness and targeting efficiency, which could efficiently kill tumor cells.

\section{Cellular uptake}

The cellular uptake and intracellular distribution of PHIS/FA mixed micelles were performed by encapsulating a fluorescent dye SRB-VE as a biomarker. SRB-VE solution was used as control. Blue represents the cell nucleus and red represents SRB-VE. As shown in Figure 5A, from the merged channels, it was evident that fluorescence visualized in the cytoplasm was time dependent. Furthermore, the fluorescence intensity of SRB-VE-loaded PHIS/FA mixed micelles (PHIS/FA/SM) was higher than that of SRB-VE. This might be probably due to different cell uptake pathways of free SRB-VE molecules and micelles delivery system. Moreover, free FA was added into the culture medium to investigate whether folate receptor-mediated endocytosis was introduced. Figure 5B shows that with increased concentration of free FA, the cellular uptake of PHIS/FA/SM decreased. The results suggested that folate receptor-mediated endocytosis was involved in the uptake of PHIS/FA mixed micelles against tumor cells.

\section{In vivo imaging}

To monitor tumor accumulation and evaluate tumor-targeting properties of PHIS/FA micelles in vivo, a noninvasive and real time-near infrared optical imaging was employed. As shown in Figure 6A, PHIS/FA/DiR displayed effective tumor targeting efficiency and sustained presence at tumor sites. The strongest fluorescence was obtained after treated with PHIS/FA/DiR for $24 \mathrm{~h}$. Afterward, the fluorescence lasted for more than $48 \mathrm{~h}$ at tumor sites and showed weak accumulation in body organs. However, most of the
A

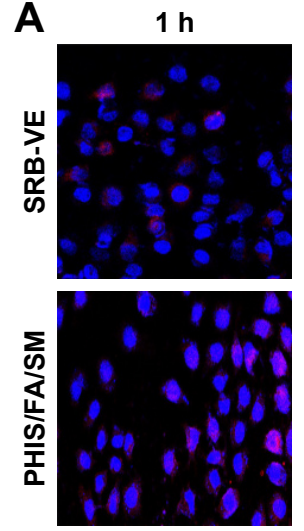

B

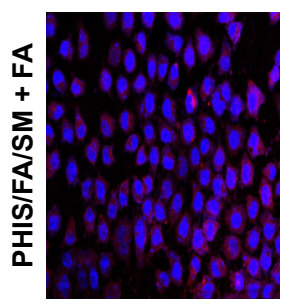

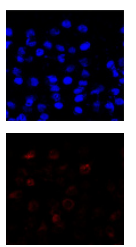
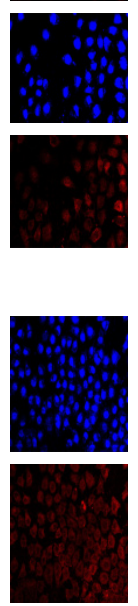

$2 \mathrm{~h}$

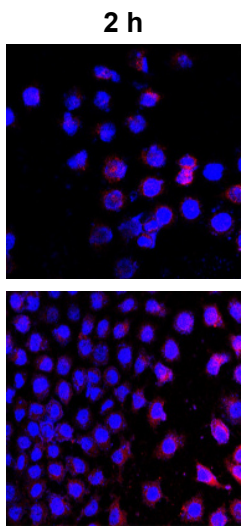

$0.002 \mathrm{mM}$

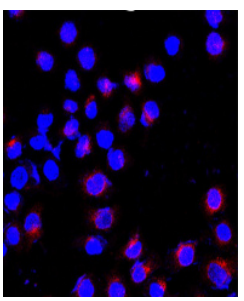

$4 \mathrm{~h}$
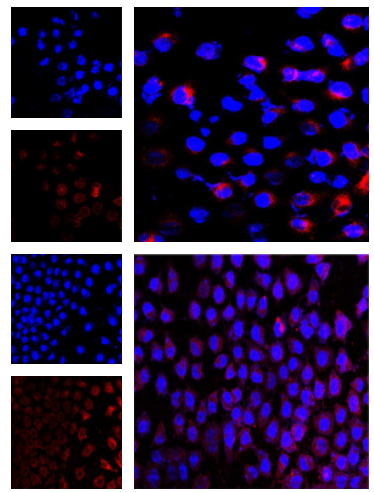

$0.1 \mathrm{mM}$

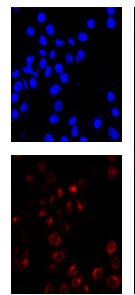

$6 \mathrm{~h}$
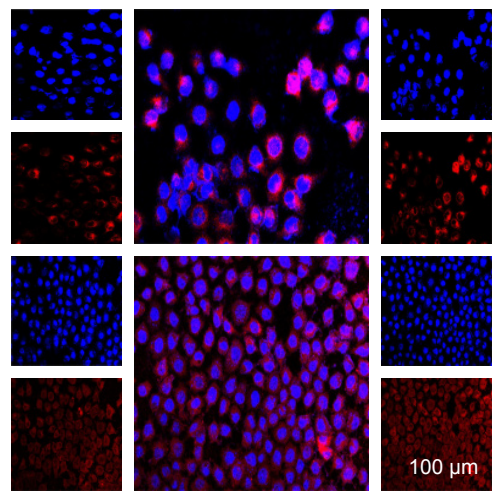

$1 \mathrm{mM}$
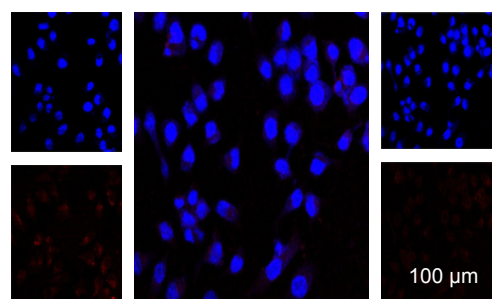

Figure 5 CLSM images of MCF-7 cells incubated with SRB-VE and PHIS/FA/SM for I, 2, 4, and $6 \mathrm{~h}$ (A) and with PHIS/FA/SM and FA (free of FA, $0.002,0.1$, and I mM) for $4 \mathrm{~h}$ (B). Blue, fluorescence of DAPI; red, fluorescence of SRB-VE. Scale bar: $100 \mu \mathrm{m}$; magnification $\times 20$.

Abbreviations: CLSM, confocal laser scanning microscopy; MPEG, poly(ethylene glycol) methyl ether; PHIS, poly(histidine); SRB-VE, sulforhodamine B-(+)- $\alpha$-tocopherol; FA, folic acid; PHIS/FA/SM, SRB-VE-loaded MPEG-PHIS/FA-PEG-VE mixed micelles; DAPI, 4',6-diamidino-2-phenylindole. 
administered DiR solution accumulated in liver and spleen. Most of the organs (liver, heart, lung, spleen, and kidney) and tumors were isolated post-injection $48 \mathrm{~h}$ and the ex vivo images are shown in Figure 6B. The PHIS/FA/DiR showed stronger fluorescence intensity in tumor sites and weaker fluorescence intensity in liver and spleen compared to the fluorescence intensity obtained by DiR solution. This might be due to the biodistribution of DiR was changed after encapsulating DiR into the mixed micelle delivery system, and more DiR selectively residence at tumor sites, and less accumulation in circulation and in healthy organs. ${ }^{50}$ From current experimental results, we may deduce that the specific accumulation of PHIS/FA micelle in tumor tissues might be due to the specific ligand FA, and extended circulation time might be due to the PEG block.

\section{Antitumor efficacy}

To investigate the antitumor efficacy and assess the toxicity of the mixed micelles, the tumor volume and body weight of tumor-bearing mice were measured after being treated with saline, Taxol, PTX-VE solution, and PHIS/FA/PM solution at a dose of $5 \mathrm{mg} / \mathrm{kg}$. During 15-day treatment, compared with the saline group, all the other groups exhibited different degrees of tumor inhibitory activity. As shown in Figure 7A, compared with the tumor volume of the saline group, which was regarded as normal without any treatment, the Taxol group and PTX-VE group showed similar tumor growth inhibitory effect with an average tumor volume of $589.42 \mathrm{~mm}^{3}$ and $586.27 \mathrm{~mm}^{3}$, respectively. In addition, PHIS/FA/PM displayed the most effective inhibitory activity with an average tumor volume of $261.76 \mathrm{~mm}^{3}$. Thus, the drug-loaded mixed micelles showed intensive antitumor efficacy, probably due to its accumulation at target tumor sites and accelerated release in tumor cells. Changes in body weight are associated with the acute toxicity of formulation. Figure 7B shows the change in body weight of different groups. Mice treated with saline and Taxol demonstrated a minimal weight loss at first 5 days and gradually recovered after that period. This might be due to the rapid growth of tumor and a decline in mice body weight gain. However, PHIS/FA/PM and PTX-VE groups showed a steady gain in body weight with minimal growth of tumors.

Then, the tumor tissues were excised and weighed to calculate the TIR (Figure 7C and D). Commercially available Taxol and PTX-VE solution exhibited similar suppression ability with a TIR of $54.58 \%$ and $59.89 \%$, respectively. PHIS/FA/PM
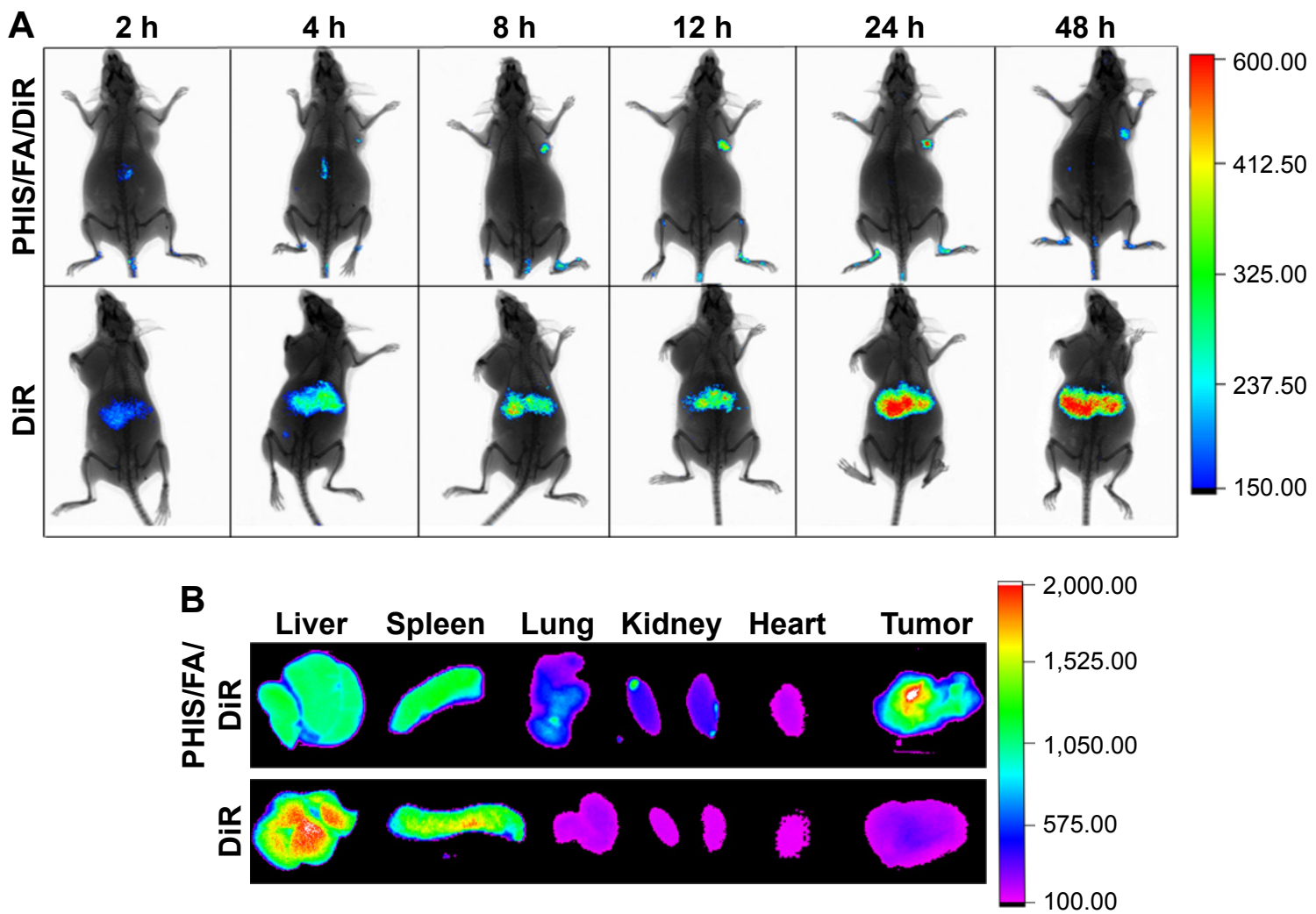

Figure 6 In vivo fluorescent images of tumor-bearing mice administrated with PHIS/FA/DiR or DiR at different time points (A) and isolated heart, liver, spleen, lung, kidney, and tumor after administration for $48 \mathrm{~h}(\mathrm{~B})$.

Abbreviations: DiR, fluorescent dyes; MPEG, poly(ethylene glycol) methyl ether; PHIS, poly(histidine); FA, folic acid; PHIS/FA/DiR, DiR-loaded MPEG-PHIS/FA-PEG-VE mixed micelles. 

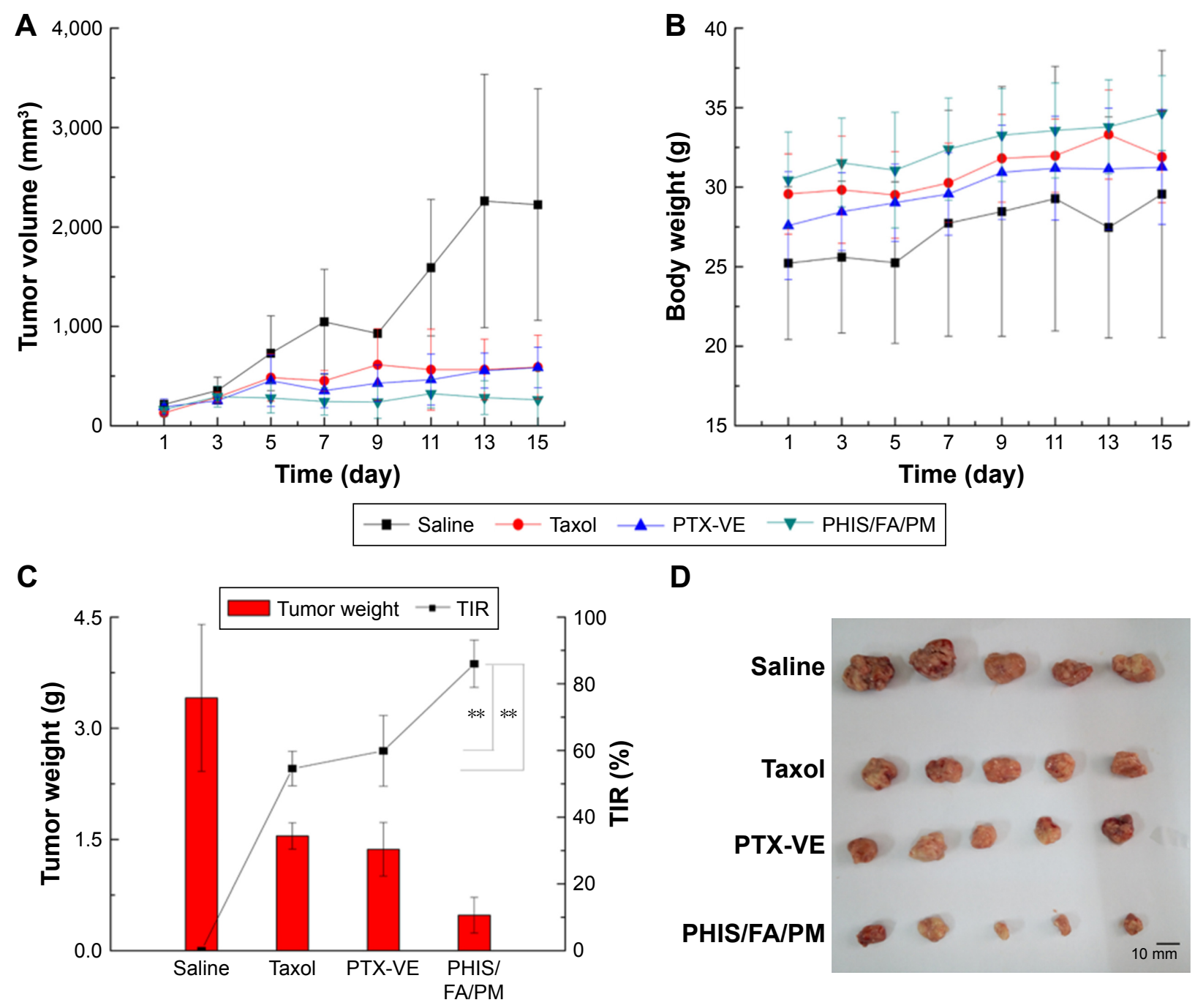

Figure 7 Changes in tumor volume (A) and body weight (B) of tumor-bearing mice administrated with saline, Taxol, PTX-VE, and PHIS/FA/PM. Tumor weight and tumor inhibition rate (TIR) of various groups (C) and image of excised tumors (D). $* * P<0.01$.

Abbreviations: PTX-VE, paclitaxel-(+)- $\alpha$-tocopherol; MPEG, poly(ethylene glycol) methyl ether; PHIS, poly(histidine); FA, folic acid; PHIS/FA/PM, PTX-VE-loaded MPEG-PHIS/FA-PEG-VE mixed micelles.

showed significant inhibitory effect with a TIR of $85.97 \%$, which was 1.44- and 1.57-fold of PTX-VE and Taxol, respectively. Therefore, it can be concluded that drug-loaded micelles fabricated by $\mathrm{pH}$-sensitive copolymer MPEG-PHIS and FA-targeted copolymer FA-PEG-VE provided effective tumor inhibitory efficacy and minimal side effects.

\section{Conclusion}

In this study, we successfully prepared a mixed micelle system fabricated by MPEG-PHIS and FA-PEG-VE, which is stable at normal $\mathrm{pH}$ and whose $\mathrm{pH}$ can be fine-tuned at acidic $\mathrm{pH}$ so as to deliver PTX-VE at target tumor sites and to obtain effective antitumor activity. It has been confirmed that the mixed micelles had a uniform particle size and $\mathrm{pH}-$ sensitive characteristics. In vitro cell studies demonstrated
$\mathrm{pH}$ responsiveness and FA-targeting capacity of the mixed micelles against MCF-7 cells. Effective tumor targeted accumulation and sustained presence at tumor sites were observed through in vivo imaging. Most importantly, the prepared mixed micelles could significantly inhibit tumor growth. Therefore, we hypothesize that MPEG-PHIS/FA-PEG-VE mixed micelle system is expected to be a potential carrier to deliver antitumor drugs in case of antitumor therapy.

\section{Acknowledgments}

This work was supported by the Natural Science Foundation of Liaoning Province (2015020729), the Scientific Research Foundation for the Returned Overseas Chinese Scholars, State Education Ministry, and the Open Fund of Key Laboratory of Ministry of Education for TCM Viscera-State Theory 
and Applications, Liaoning University of Traditional Chinese Medicine (zyzx1608). We thank Master Pingfei Li for his help in revising this article.

\section{Disclosure}

The authors report no conflicts of interest in this work.

\section{References}

1. Gonzalez-Angulo AM, Morales-Vasquez F, Hortobagyi GN. Overview of resistance to systemic therapy in patients with breast cancer. $A d v$ Exp Med Biol. 2007;608:1-22.

2. Lee ES, Gao Z, Bae YH. Recent progress in tumor $\mathrm{pH}$ targeting nanotechnology. J Control Release. 2008;132(3):164-170.

3. Anand A, Huberman M, Cavaletti G, Tredici G. Peripheral neurotoxicity of taxol in patients previously treated with cisplatin. Cancer. 1995;76(5) 916-917.

4. Carelle N, Piotto E, Bellanger A, Germanaud J, Thuillier A, Khayat D. Changing patient perceptions of the side effects of cancer chemotherapy. Cancer. 2002;95(1):155-163.

5. Schinkel AH, Jonker JW. Mammalian drug efflux transporters of the ATP binding cassette (ABC) family: an overview. Adv Drug Deliv Rev. 2003;55(1):3-29.

6. Kunjachan S, Rychlik B, Storm G, Kiessling F, Lammers T. Multidrug resistance: physiological principles and nanomedical solutions. Adv Drug Deliv Rev. 2013;65(13-14):1852-1865.

7. Sawant RM, Hurley JP, Salmaso S, et al. "SMART" drug delivery systems: double-targeted $\mathrm{pH}$-responsive pharmaceutical nanocarriers. Bioconjug Chem. 2006;17(4):943-949.

8. Gaucher G, Marchessault RH, Leroux JC. Polyester-based micelles and nanoparticles for the parenteral delivery of taxanes. $J$ Control Release. 2010;143(1):2-12.

9. Liu Y, Wang W, Yang J, Zhou C, Sun J. pH-sensitive polymeric micelles triggered drug release for extracellular and intracellular drug targeting delivery. Asian J Pharm Sci. 2013;8(3):159-167.

10. Parker N, Turk MJ, Westrick E, Lewis JD, Low PS, Leamon CP. Folate receptor expression in carcinomas and normal tissues determined by a quantitative radioligand binding assay. Anal Biochem. 2005;338(2): 284-293.

11. Müller C, Schubiger PA, Schibli R. In vitro and in vivo targeting of different folate receptor-positive cancer cell lines with a novel $99 \mathrm{mTc}-$ radiofolate tracer. Eur J Nucl Med Mol Imaging. 2006;33(10): 1162-1170.

12. Chaidarun SS, Eggo MC, Sheppard MC, Stewart PM. Expression of epidermal growth factor (EGF), its receptor, and related oncoprotein (erbB-2) in human pituitary tumors and response to EGF in vitro. Endocrinology. 1994;135(5):2012-2021.

13. Qiu L, Qiao M, Chen Q, et al. Enhanced effect of $\mathrm{pH}$-sensitive mixed copolymer micelles for overcoming multidrug resistance of doxorubicin. Biomaterials. 2014;35(37):9877-9887.

14. Susa M, Iyer AK, Ryu K, et al. Doxorubicin loaded polymeric nanoparticulate delivery system to overcome drug resistance in osteosarcoma. BMC Cancer. 2009;9(1):399.

15. Wang C, Feng L, Yang X, Wang F, Lu W. Folic acid-conjugated liposomal vincristine for multidrug resistant cancer therapy. Asian J Pharm Sci. 2013;8(2):118-127.

16. Biswas S, Kumari P, Lakhani P, Ghosh B. Recent advances in polymeric micelles for anti-cancer drug delivery. Eur J Pharm Sci. 2016;83: 184-202.

17. Oh KT, Yin H, Lee ES, Bae YH. Polymeric nanovehicles for anticancer drugs with triggering release mechanisms. J Mater Chem. 2007;17: 3987-4001.

18. Pack DW, Hoffman AS, Pun S, Stayton PS. Design and development of polymers for gene delivery. Nat Rev Drug Discov. 2005;4(7): $581-593$.
19. Zhou Z, Badkas A, Stevenson M, Lee JY, Leung YK. Herceptin conjugated PLGA-PHis-PEG pH sensitive nanoparticles for targeted and controlled drug delivery. Int J Pharm. 2015;487(1-2):81-90.

20. Wong HL, Bendayan R, Rauth AM, Xue HY, Babakhanian K, Wu XY. A mechanistic study of enhanced doxorubicin uptake and retention in multidrug resistant breast cancer cells using a polymer-lipid hybrid nanoparticle system. J Pharmacol Exp Ther. 2006;317(3): $1372-1381$.

21. Wang F, Jiang X, Yang DC, Elliott RL, Head JF. Doxorubicin-galliumtransferrin conjugate overcomes multidrug resistance: evidence for drug accumulation in the nucleus of drug resistant MCF-7/ADR cells. Anticancer Res. 2000;20(20A):799-808.

22. Engin K, Leeper DB, Cater JR, Thistlethwaite AJ, Tupchong L, McFarlane JD. Extracellular pH distribution in human tumours. Int J Hyperthermia. 1995;11(2):211-216.

23. van Sluis R, Bhujwalla ZM, Raghunand N, et al. In vivo imaging of extracellular pH using 1H MRSI. Magn Reson Med. 1999;41(4): $743-750$.

24. Volk T, Jähde E, Fortmeyer HP, Glüsenkamp KH, Rajewsky MF. $\mathrm{pH}$ in human tumour xenografts: effect of intravenous administration of glucose. Br J Cancer. 1993;68(3):492-500.

25. Yin H, Lee ES, Kim D, Lee KH, Oh KT, Bea YH. Physicochemical characteristics of $\mathrm{pH}$-sensitive poly(L-histidine)-b-poly(ethylene glycol)/ poly(L-lactide)-b-poly(ethylene glycol) mixed micelles. $J$ Control Release. 2008;126(2):130-138.

26. Lee ES, Shin HJ, Na K, Bea YH. Poly(L-histidine)-PEG block copolymer micelles and $\mathrm{pH}$-induced destabilization. $J$ Control Release. 2003;90(3):363-374.

27. Lee ES, Na K, Bea YH. Doxorubicin loaded $\mathrm{pH}$-sensitive polymeric micelles for reversal of resistant MCF-7 tumor. $J$ Control Release. 2004;103(2):405-418.

28. Pack DW, Putnam D, Langer R. Design of imidazole-containing endosomolytic biopolymers for gene delivery. Biotechnol Bioeng. 2000;67(2): 217-223.

29. Putnam D, Zelikin AN, Izumrudov VA, Langer R. PolyhistidinePEG:DNA nanocomposites for gene delivery. Biomaterials. 2003; 24(24):4425-4433.

30. Oh KT, Lee ES, Kim D, Bae YH. L-histidine based pH-sensitive anticancer drug carrier micelle: reconstitution and brief evaluation of its systemic toxicity. Int J Pharm. 2008;358(1-2):177-183.

31. Wu H, Zhu L, Torchilin VP. pH-sensitive poly(histidine)-PEG/DSPEPEG co-polymer micelles for cytosolic drug delivery. Biomaterials. 2013; 34(4):1213-1222.

32. Tian L, Bae YH. Cancer nanomedicines targeting tumor extracellular pH. Colloids Surf B Biointerfaces. 2012;99:116-126.

33. Lee ES, Oh KT, Kim D, Youn YS, Bae YH. Tumor pH-responsive flower-like micelles of poly(L-lactic acid)-b-poly(ethylene glycol)-bpoly(L-histidine). J Control Release. 2007;123(1):19-26.

34. Lee ES, Na K, Bae YH. Polymeric micelle for tumor $\mathrm{pH}$ and folatemediated targeting. J Control Release. 2003;91(1-2):103-113.

35. Li X, Yang $\mathrm{X}$, Lin $\mathrm{Z}$, et al. A folate modified $\mathrm{pH}$ sensitive targeted polymeric micelle alleviated systemic toxicity of doxorubicin (DOX) in multi-drug resistant tumor bearing mice. Eur J Pharm Sci. 2015;76: 95-101.

36. Kim D, Lee ES, Oh KT, Gao ZG, Bae YH. Doxorubicin-loaded polymeric micelle overcomes multidrug resistance of cancer by doubletargeting folate receptor and early endosomal pH. Small. 2008;4(11): 2043-2050.

37. Ma Y, Liu D, Wang D, et al. Combinational delivery of hydrophobic and hydrophilic anticancer drugs in single nanoemulsions to treat MDR in cancer. Mol Pharm. 2014;11(8):2623-2630.

38. Yang X, Wang D, Ma Y, et al. Theranostic nanoemulsions: codelivery of hydrophobic drug and hydrophilic imaging probe for cancer therapy and imaging. Nanomedicine (Lond). 2014;9(18):2773-2785.

39. Di Y, Gao Y, Gai X, et al. Co-delivery of hydrophilic gemcitabine and hydrophobic paclitaxel into novel polymeric micelles for cancer treatment. RSC Adv. 2017;7(39):24030-24039. 
40. Booth DS, Avila-Sakar A, Cheng Y. Visualizing proteins and macromolecular complexes by negative stain EM: from grid preparation to image acquisition. $J$ Vis Exp. 2011;(58):spii:3227.

41. Liu S-Q, Wiradharma N, Gao S-J, Tong WY, Yang Y-Y. Bio-functional micelles self-assembled from a folate-conjugated block copolymer for targeted intracellular delivery of anticancer drugs. Biomaterials. 2007;28(7):1423-1433.

42. Lu J, Zhao W, Huang Y, et al. Targeted delivery of doxorubicin by folic acid-decorated dual functional nanocarrier. Mol Pharma. 2014;11(11): 4164-4178.

43. Stolnik S, Heald CR, Neal J, et al. Polylactide-poly(ethylene glycol) micellar-like particles as potential drug carriers: production, colloidal properties and biological performance. J Drug Target. 2001;9(5): 361-378.

44. Ge Z, Liu S. Functional block copolymer assemblies responsive to tumor and intracellular microenvironments for site-specific drug delivery and enhanced imaging performance. Chem Soc Rev. 2013;42(17):7289-7325.

45. Liu M, Zhou Z, Wang X, et al. Formation of poly(L,D-lactide) spheres with controlled size by direct dialysis. Polymer. 2007;48(19): 5767-5779.
46. Zhang Y, Jiang M, Zhao J, Zhou J, Chen D. Hollow spheres from shell crosslinked, noncovalently connected micelles of carboxyl-terminated polybutadiene and poly(vinyl alcohol) in water. Macromolecules. 2004;37(4):1537-1543.

47. Park KH, Song $\mathrm{HC}, \mathrm{Na} \mathrm{K}$, et al. Ionic strength-sensitive pullulan acetate nanoparticles (PAN) for intratumoral administration of radioisotope; ionic strength-dependent aggregation behavior and 99mTechnetium retention property. Colloids Surf B Biointerfaces. 2007;59(1):16-23.

48. Scherliess R. The MTT assay as tool to evaluate and compare excipient toxicity in vitro on respiratory epithelial cells. Int J Pharm. 2011; 411(1-2):98-105.

49. Zhang X, Chen D, Ba S, et al. Poly(L-histidine) based triblock copolymers: $\mathrm{pH}$ induced reassembly of copolymer micelles and mechanism underlying endolysosomal escape for intracellular delivery. Biomacromolecules. 2014;15(11):4032-4045.

50. Wang CY, Huang L. Polyhistidine mediates an acid-dependent fusion of negatively charged liposomes. Biochemistry. 1984;23(19): 4409-4416. 


\section{Supplementary materials}

The synthesis of poly(ethylene glycol) methyl ether-poly(histidine) (MPEG-PHIS) Materials

N-(t-butyloxycarboryl)-1-(2,4-dinitrophenyl)-L-histidine [Boc-His(DNP)-OH] was purchased from GL Biochem Ltd (Shanghai, China). MPEG ${ }_{2000}-\mathrm{NH}_{2}$ was purchased from Sinopeg Biological Technology Co., Ltd (Xiamen, China). Tetrahydrofuran (THF), dichloro sulfoxide $\left(\mathrm{SOCl}_{2}\right)$, and dimethyl sulfoxide (DMSO) were purchased from Damao Chemical Reagent Factory (Tianjin, China). 2-Mercaptoethanol was purchased from Haiqu Chemical Industry Co., Ltd (Shanghai, China). Dimethylformamide (DMF) was purchased from Yongda Chemical Reagent Co., Ltd (Tianjin, China).

\section{Synthesis of MPEG-PHIS}

MPEG-PHIS was synthesized according to the previous report. ${ }^{1}$ The synthetic route is shown in Figure S2. BocHis(DNP)-OH (2 g) was dissolved in $15 \mathrm{~mL}$ dry THF under a nitrogen atmosphere, and $1.2 \mathrm{~mL}$ redistilled $\mathrm{SOCl}_{2}$ was added and reacted at room temperature for $2 \mathrm{~h}$.
The sediment (DNP-NCA·HCl) was obtained after washing by anhydrous ether and dried under vacuum overnight. Then, DNP-NCA.HCl (1.03 g) was dissolved in dry DMF. After complete dissolution, $421 \mathrm{mg}$ sodium carbonate was added and stirred at room temperature for $1 \mathrm{~h}$ under a nitrogen atmosphere. The MPEG- $\mathrm{NH}_{2}$ dissolved in DMF was then added in drops to the reaction solution, and the mixture was stirred at room temperature for another $72 \mathrm{~h}$. A total of $1.12 \mathrm{~g}$ MPEG-poly(Nim-DNP-histidine) was obtained after filtration and dried under vacuum overnight. Afterward, MPEGpoly(Nim-DNP-histidine) was dissolved in $30 \mathrm{~mL}$ dimethyl sulfoxide (DMSO), and $15 \mathrm{~mL}$ of 2-mercaptoethanol was added and stirred at room temperature for $12 \mathrm{~h}$. After the reaction was completed, the reaction solution was dialyzed against deionized water for 3 days and the final product was obtained after lyophilization. The product was confirmed by ${ }^{1} \mathrm{H}-\mathrm{NMR}$ and spectrum is shown in Figure S3: ${ }^{1} \mathrm{H}-\mathrm{NMR}$ (400 Hz, DMSO-d ${ }_{6}$ with TMS): $\delta 10.16(\mathrm{a},-\mathrm{NH}-), \delta 7.98$ (b, $-\mathrm{N}=\mathrm{CH}-), \delta 7.51$ (g, $-\mathrm{CONH}-), \delta 7.26(\mathrm{c},-\mathrm{C}=\mathrm{CH}-$ ), $\delta 4.57\left(\mathrm{e},-\mathrm{NH}_{2}\right), \delta 3.68\left(\mathrm{i},-\mathrm{CH}_{2}-\right), \delta 3.51\left(\mathrm{j},-\mathrm{CH}_{2}-\right), \delta 3.37$ $\left(\mathrm{h},-\mathrm{CH}_{2}-\right), \delta 3.24\left(\mathrm{k},-\mathrm{OCH}_{3}\right), \delta 2.12\left(\mathrm{~d},-\mathrm{CH}_{2}-\right)$.

A

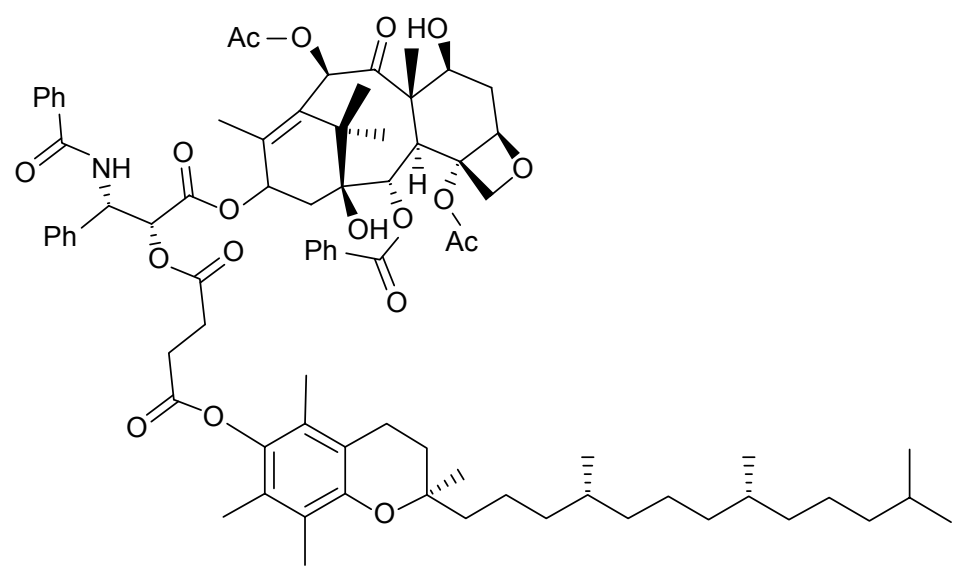

B

PTX-VE

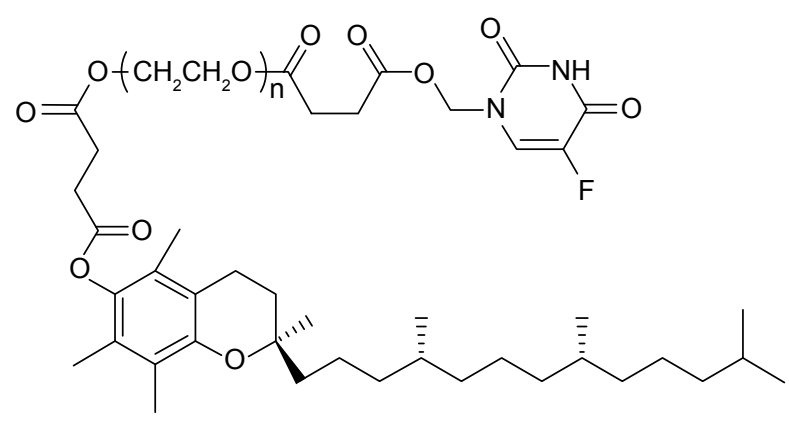

SRB-VE

Figure SI Chemical structure of PTX-VE (A) and SRB-VE (B).

Abbreviations: PTX-VE, paclitaxel-(+)- $\alpha$-tocopherol; SRB-VE, sulforhodamine $B-(+)-\alpha$-tocopherol. 
<smiles>CC1CC1C</smiles>

Boc-His(DNP)-OH<smiles>O=C1NC(Cc2cncn2-c2ccc([N+](=O)[O-])cc2[N+](=O)[O-])C(=O)O1</smiles>

DNP-NCA·HCI<smiles>[B]C(C)(C)COC(C)CCNC(=O)C(Cc1cncn1-c1ccc([N+](=O)[O-])cc1[N+](=O)[O-])NC</smiles>

MPEG-poly(Nim-DNP-histidine)<smiles>COCCOCCNC(=O)C(Cc1cncn1-c1ccccc1)NCCC(C)(C)C</smiles>

Poly(L-histidine)

Figure S2 Chemical synthesis of MPEG-PHIS.

Notes: Reagents and condition: (A) SOCl, THF, RT, 2 h; (B) MPEG-NH, RT, 72 h, Na $\mathrm{CO}_{3}$; (C) 2-mercaptoethanol, DMSO, 12 h. Abbreviations: MPEG-PHIS, poly(ethylene glycol) methyl ether-poly(histidine); DMSO, dimethyl sulfoxide; RT, room temperature.

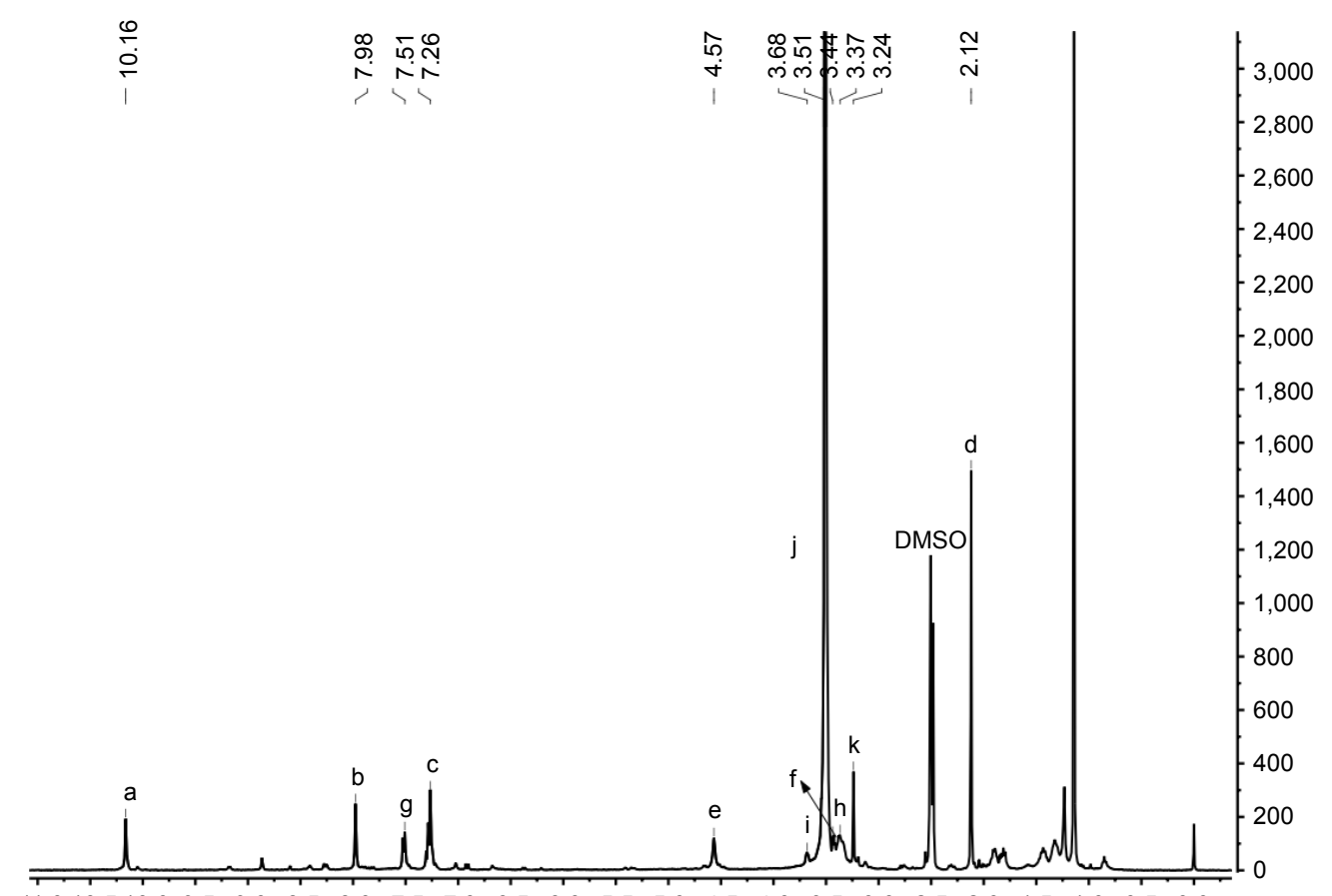

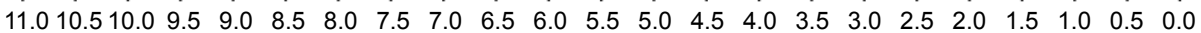

f1 (ppm)

Figure S3 'H-NMR spectrum of MPEG-PHIS.

Abbreviations: MPEG-PHIS, poly(ethylene glycol) methyl ether-poly(histidine); DMSO, dimethyl sulfoxide. 


\section{Reference}

1. Li X, Yang X, Lin Z, et al. A folate modified $\mathrm{pH}$ sensitive targeted polymeric micelle alleviated systemic toxicity of doxorubicin (DOX) in multidrug resistant tumor bearing mice. Eur J Pharm Sci. 2015;76:95-101.

International Journal of Nanomedicine

\section{Publish your work in this journal}

The International Journal of Nanomedicine is an international, peerreviewed journal focusing on the application of nanotechnology in diagnostics, therapeutics, and drug delivery systems throughou the biomedical field. This journal is indexed on PubMed Central, MedLine, CAS, SciSearch ${ }^{\circledR}$, Current Contents ${ }^{\circledR} /$ Clinical Medicine,
Journal Citation Reports/Science Edition, EMBase, Scopus and the Elsevier Bibliographic databases. The manuscript management system is completely online and includes a very quick and fair peer-review system, which is all easy to use. Visit http://www.dovepress.com/ testimonials.php to read real quotes from published authors.

Submit your manuscript here: http://www.dovepress.com/international-journal-of-nanomedicine-journal 